\title{
Implicações da desinformação e da infodemia no contexto da pandemia da Covid-19
}

\author{
Implications of disinformation and infodemic in the context of the Covid-19 pandemic \\ Implicaciones de la desinformación y la infodemia en el contexto de la pandemia Covid-19
}

Recebido: 15/02/2021 | Revisado: 22/02/2021 | Aceito: 23/02/2021 | Publicado: 26/02/2021

\author{
Hélio Souza de Cristo \\ ORCID: https://orcid.org/0000-0003-1219-9304 \\ Universidade Federal da Bahia, Brasil \\ E-mail: helio-87@hotmail.com \\ Teófanes de Assis Santos \\ ORCID: https://orcid.org/0000-0003-2055-7677 \\ Universidade Federal da Bahia, Brasil \\ E-mail: teofanes.assis@ufba.br \\ Flávio Eduardo Aoki Horita \\ ORCID: https://orcid.org/0000-0002-7138-9223 \\ Universidade Federal do ABC, Brasil \\ E-mail: flavio.horita@ufabc.edu.br \\ Hugo Saba \\ ORCID: https://orcid.org/0000-0001-8402-6416 \\ Universidade do Estado da Bahia, Brasil \\ E-mail: hugosaba@gmail.com
}

\begin{abstract}
Resumo
A disseminação de notícias falsas representa risco para a saúde das coletividades por suas potenciais implicações nas esferas socioeconômica, política e cultural. Esse estudo objetiva refletir sobre as implicações das notícias falsas para a saúde das populações. Trata-se de um trabalho de abordagem qualitativa e exploratória de revisão bibliográfica, que analisa fake news veiculadas nas mídias sociais entre março e maio de 2020. Assim, questiona-se: quais as possíveis implicações das fake news para a saúde das populações? Que efeitos sociopolíticos e econômicos existem na disseminação de fake news no campo da Saúde Pública? Existiriam intencionalidades por parte das autoridades públicas ao difudir fake news? Os resultados sugerem que os debates sobre fake news e saúde no contexto da pandemia da Covid-19 se constituem um paradigma atual. Os resultados apontam, ainda, que a falta de acesso à diversidade de fontes de informações confiáveis contribui para o aumento da vulnerabilidade em saúde.
\end{abstract}

Palavras-chave: Fake news; Infodemia; Coronavírus; Covid-19; Saúde pública.

\begin{abstract}
The dissemination of false news represents a risk to the health of communities due to its potential implications in the socioeconomic, political and cultural spheres. This study aims to reflect on the implications of false news for the health of populations. It is a work of qualitative and exploratory approach to bibliographic review, which analyzes fake news broadcast on social media between March and May 2020. Thus, the question is: what are the possible implications of fake news for the health of populations? What socio-political and economic effects are there in the spread of fake news in the field of Public Health? Were there intentions on the part of public authorities to spread fake news? The results suggest that the debates about fake news and health in the context of the Covid-19 pandemic are a current paradigm. The results also point out that the lack of access to the diversity of sources of reliable information contributes to the increase in health vulnerability.
\end{abstract}

Keywords: Fake news; Infodemic; Coronavirus; Covid-19; Public health.

\section{Resumen}

La difusión de noticias falsas representa un riesgo para la salud de las comunidades por sus potenciales implicaciones en el ámbito socioeconómico, político y cultural. Este estudio tiene como objetivo reflexionar sobre las implicaciones de las noticias falsas para la salud de las poblaciones. Se trata de un trabajo de abordaje cualitativo y exploratorio de revisión bibliográfica, que analiza las fake news difundidas en redes sociales entre marzo y mayo de 2020. Así, la pregunta es: ¿cuáles son las posibles implicaciones de las fake news para la salud de las poblaciones? ¿Qué efectos sociopolíticos y económicos tiene la difusión de noticias falsas en el ámbito de la Salud Pública? ¿Hubo intenciones por parte de las autoridades públicas de difundir noticias falsas? Los resultados sugieren que los debates sobre fake news y salud en el contexto de la pandemia Covid-19 son un paradigma actual. Los resultados también señalan que la falta de acceso a la diversidad de fuentes de información confiable contribuye al aumento de la vulnerabilidad en salud.

Palabras clave: Noticias falsas; Infodemia; Coronavirus; COVID-19; Salud pública. 


\section{Introdução}

A imprensa popular americana iniciou em 1830 a vinculação de notícias de modo neutro e direto, até então as notícias seguiam o viés de interesses políticos. Com o tempo, a imprensa começa a separar a opinião e a notícia, dando à notícia um caráter profissional focado na informação pura e objetiva (Langbecker, Castellanos, \& Catalan-Matamoros, 2019). Com o passar dos anos, a popularização da impressa e o surgimento de meios digitais de vinculação, trouxe um maior dinamismo na produção de notícias e suas vinculações.

A pandemia de Covid-19 tem gerado apreensão em diversos países do mundo. Num período em que, muitas vezes, os únicos meios de acesso à informação para a grande parte da população mundial são as mídias sociais e que as informações produzidas e compartilhadas assumem a condição de verdades, a disseminação de notícias falsas (fake news) por meio de fotos, vídeos, áudios e textos afetam, diretamente, o campo da comunicação, a credibilidade das informações, da economia, das relações sociais e, sobretudo, da Saúde Pública.

No campo da Ciências Sociais, o termo fake news pode ser entendido como a produção e disseminação de notícias de conteúdos falsos e informações inverídicas que, estratégica e intencionalmente, têm o objetivo de desinformar e provocar a falta de credibilidade nas fontes confiáveis de informação. "Recentemente, o termo notícias falsas tem sido usado principalmente para se referir ao conteúdo que apresenta o estilo de notícias convencionais, mas que se destina, deliberadamente, a desinformar" (Sacramento \& Paiva, 2020, p. 100).

Estudo conduzido por pesquisadores do Massachusetts Institute of Technology (Vosoughi, Roy, \& Aral, 2018), referência nos estudos sobre o fenômeno das fake news, verificou que a disseminação de notícias falsas através de uma rede social tem $70 \%$ de chances a mais de ser propagadas do que uma notícia real. Uma possível resposta para o porquê de notícias dessa natureza se espalharem mais rapidamente pode residir, segundo a pesquisa, no caráter criativo e inovador que têm.

No Brasil, pesquisa de 2020 desenvolvida por Galhardi e Minayo e publicada pela Fundação Oswaldo Cruz (Fiocruz) (Brasil, 2020), chama a atenção para o fato que quase $74 \%$ das mensagens que circularam entre março e abril no aplicativo WhatsApp acerca da Covid-19 são informações falsas, seguindo-se - no ranking de circulação sobre a pandemia - o Facebook com quase $16 \%$ e o Instagram com 10,5\%. A pesquisa aponta que as informações falsas disseminadas, inclusive utilizando o nome da Fiocruz como remetente das informações, vão desde a orientação para as populações não acreditarem na Covid-19 às indicações de produção de receitas caseiras sem nenhum tipo de comprovação científica.

O diretor geral da Organização Mundial de Saúde, Tedros Adhanom Ghebreyesus, considerou em sua fala na Conferência de Segurança de Munique, em 15 de fevereiro, que o mundo vive um momento de desinformação - que denominou de infodemia - paralelamente à disseminação da Covid-19, o que representa um risco elevado à Saúde Pública (Zarocostas, 2020; Who, 2020). A infodemia é um termo análogo à epidemia que busca explicar a rápida velocidade com que informações falsas sobre a Covid-19 têm sido veiculadas em contraposição às informações oficiais e que põem em risco a saúde das populações.

Pierro (2020) entende a infodemia como a

difusão massiva de desinformação, mentiras e rumores sobre a pandemia, comprometendo o acesso a dados com respaldo de cientistas e autoridades sanitárias. Além das notícias falsas, hoje conhecidas como fake news, o crescimento vertiginoso no volume de informações nem sempre precisas, divulgadas diariamente pelos meios de comunicação, também pode desnortear as pessoas (Who, 2020).

Como produtoras de discursos através de manchetes, noticiários e mensagens, as fake news são alvo de discussão e estudo neste trabalho, que tem como objetivo refletir sobre as implicações das fake news produzidas sobre a Covid-19, levando em consideração as maneiras pelas quais a propagação de informações falsas pode potencialmente interferir na Saúde Pública. 
Importante destacar que outros estudos sobre as implicações da infodemia têm sido desenvolvidos em contextos nacionais e internacionais, o que revela a efervescência da temática e a necessidade de discussões que contemplem os diversos setores da sociedade (Gallotti, et al., 2020; Mesquita, et al., 2020).

\section{Metodologia}

Visando alcançar o objetivo que o fundamenta, este trabalho de abordagem qualitativa e exploratória (Minayo, 2013; Pereira, et al., 2018) subsidiado por uma revisão de literatura, apresenta em sua discussão e análise, uma seleção de fake news disseminadas nas mídias sociais entre os meses de março e maio de 2020 referentes à Covid-19.

O caráter exploratório do trabalho se dá pelo fato que, metodologicamente, objetiva explorar, por meio da revisão de literatura e análise de fake news disseminadas nas mídias sociais referentes à Covid-19, um campo de estudo, até então, pouco ou não suficientemente estudado e explorado, tendo em vista a recente emergência e efervescência da pandemia do COVID-19, ocasionada pelo SARS-CoV-2.

Importante salientar que a pesquisa qualitativa, enquanto campo que abarca uma série de metodologias de pesquisa, possibilita a construção de novos olhares e abordagens sobre estudos

relacionados a processos sociais, bem como a construção de conhecimento e a revisão de conceitos à luz do objeto estudado. Visto pela perspectiva social, o campo da pesquisa qualitativa dialoga com múltiplos processos de investigações científicas que "tratam do ser humano em sociedade, de suas relações e instituições, de sua história e de sua produção simbólica” (Minayo, 2010, p. 34).

Durante a fase de levantamento de dados, a abordagem proposta por Vom Brocke et al. (2009) ou Kitcheham e Charters (2007) foi empregada nas bases automáticas de dados PubMed e Scielo utilizando strings de busca composta por dois termos-base (ou seja, fake news e coronavírus), separados pelo operador booleano "and". De maneira a garantir uma maior cobertura no levantamento, sinônimos associados aos termos-base também foram empregados.

$\mathrm{Na}$ base PubMed, foram encontrados quatro trabalhos quando pesquisados os descritores "fake news e coronavirus", oito quando utilizados os descritores "infodemic e coronavirus" e 12 trabalhos quando pesquisados os descritores "misinformation e coronavirus". No Scielo retornou um trabalho referente aos descritores "fake news e coronavirus", zero quando utilizados os descritores "infodemic e coronavirus" e zero trabalho referente aos descritores "misinformation e coronavirus".

Além das análises feitas a partir de trabalhos selecionados nas bases PubMed e Scielo, foram incluídas outras fontes de pesquisa, a exemplos de notícias publicadas em sites de grande divulgação, como o UOL, Portal de Notícias G1 e Folha de São Paulo.

As fake news selecionadas neste trabalho, obtidas através da ferramenta "notícias" do Google e dos sistemas de identificação de fake news dos próprios sites de notícias, se configuram como elementos ilustrativos para, através dos discursos produzidos pelas suas narrativas, tecer reflexões sobre as implicações, no campo da saúde, das fake news difundidas acerca da Covid-19, buscando realizar o confronto analítico com pesquisas e evidências científico-acadêmicas que denunciam as pseudociências, a inveracidade e distorções das informações e notícias falsas disseminadas, como pode ser visto na seção a seguir. 


\section{Resultados e Discussão}

\subsection{A cultura da desinformação e seus reflexos na Saúde Pública}

Muitas são as postagens (publicações virtuais) que, embora apresentem superficialmente características que à primeira vista pareçam ser verdadeiras e contenham em suas manchetes uma estrutura discursiva similar à de fontes confiáveis, proliferam a cultura da desinformação com conteúdos de baixa qualidade ou sem o devido rigor científico.

Nesse sentido, no cenário de incertezas, medos, angústias, busca por informações, distanciamento social e estatísticas de óbitos causadas pela Covid-19 - a produção e disseminação de mensagens sobre a Covid-19 através de mídias sociais, como o Facebook, Instagram e Whatsapp, têm ocorrido de forma rápida, sem a preocupação de estar fornecendo notícias confiáveis que contribuam na compreensão da pandemia, o que é de fundamental importância (Chan, et al., 2020).

Concomitantemente aos esforços empreendidos para evitar a propagação da Covid-19, a veiculação de notícias falsas também se constitui um grande desafio científico e sanitário, principalmente dos órgãos e instituições ligados à Saúde Pública, no que diz respeito à garantia de acesso e divulgação dos dados e fatos sobre a Covid-19. Por isso, perante o cenário de propagação de desinformação, o momento requer maior grau de confiança nos processos e meios de comunicação, haja vista que a saúde se encontra em estado de risco e a propagação de informações falsas se constitui uma ameaça potencial às mudanças necessárias ao enfrentamento da pandemia da Covid-19.

As mídias sociais exercem influência e poder e, na ordem dos discursos escritos e audiovisuais, a viralização das fake news provoca - intencional e estrategicamente - comportamentos, posturas, compreensões e escolhas avessos à segurança das populações no que diz respeito à saúde física, mental, psicológica e interpessoal. Esses discursos, por sua vez, objetivam deturpar a realidade, manipular as pessoas, descredibilizar a Ciência, monopolizar as informações e, sobretudo, fortalecer a cultura da desinformação.

Nesse sentido, não é surpresa que o momento da pandemia causado pela Covid-19, também, se constitua forte alvo para produção e disseminação de fake news, cujas mensagens veiculadas - distantes da apuração e busca da veracidade assumem sentido de verdade e produzem discursos contrários à efetiva garantia da Saúde Pública. Em paralelo, este fato ainda coloca à prova a confiança nos meios de comunicação e informação, bem como nas instituições científicas e sociais, como a Organização Mundial da Saúde (OMS), o Ministério da Saúde e Secretarias de Saúde de estados e municípios.

Por este ângulo, a disseminação de informações falsas sobre a Covid-19 provoca algumas interrogações, tais como: Que efeitos as fake news podem produzir na Saúde Pública? Quais as suas intencionalidades em tempos de pandemia? A quem servem? Existem relações entre a disseminação de fake news, Saúde Pública e questões sociopolíticas? Como essas notícias podem influenciar no comportamento das pessoas em relação aos cuidados com a saúde? Como notícias dessa natureza podem interferir na credibilidade e confiança atribuídas pelas populações a órgãos como o Ministério da Saúde, a Organização Mundial da Saúde e Secretarias Estaduais e Municipais de Saúde? Quais desafios apresentam para a Saúde Pública?

Visando barrar ou amenizar a propagação de notícias dessa natureza e a sua forte influência sobre as ações de combate à Covid-19 e que reverberam não somente na saúde das populações, mas que também implicam econômica e politicamente, países de todos os continentes do mundo têm adotado medidas para o enfrentamento à infodemia. Essas ações tentam usar entre outras medidas - o mesmo meio que elas usam para se propagar: as plataformas digitais. A diferença consiste, no entanto, na qualidade da informação e no estímulo para que a população busque informações em fontes confiáveis e oficiais. Por exemplo, buscar apenas por informações validadas pela própria população ou fontes confiáveis (Pennycook \& Rand, 2019).

A luta contra a desinformação, por meio das mídias digitais, objetiva informar à população sobre a Covid-19 e sobre os sistemas de saúde, e tem contado com a colaboração e o apoio fundamentais de universidades e instituições de pesquisas, a exemplo da Universidade Johns Hopkins (Estados Unidos), a Universidade Federal de Minas Gerais (UFMG, Brasil), a Universidade de São Paulo (USP, Brasil), a Universidade Estadual de Campinas (Unicamp, Brasil), a Fundação Oswaldo Cruz 
(Brasil), a Fundação de Amparo à Pesquisa do Estado de São Paulo (Fapesp, Brasil) e o Observatório Covid-19 BR (desenvolvido por um conjunto de pesquisadores de universidades brasileiras, quais sejam: Universidade Estadual Paulista Unesp, Universidade de Brasília - UnB, Universidade Federal do ABC - UFABC, Universidade de São Paulo, Universidade Estadual de Campinas), conforme verificado por Pierro (Who, 2020).

Destaca-se, ainda, que outras ações de enfrentamento à desinformação também têm sido promovidas por instituições como a Associação Brasileira de Saúde Coletiva (Abrasco) e o Instituto de Saúde Coletiva da Universidade Federal da Bahia (Isc/Ufba) por meio de sistemáticos debates e palestras online que visam informar à população não somente sobre as características epidemiológicas da doença, mas sobre seus efeitos e repercussões na saúde e no cotidiano das pessoas.

Não há dúvidas que, no campo da Saúde Pública, onde as informações e os avanços científicos estão em constante atualização, transformação e aprimoramento, o fenômeno das fake news pode ser sensivelmente perigoso para a saúde individual e das coletividades, mas também para a economia e para a subsistência dos sistemas de saúde.

\subsection{Caso da cloroquina no Brasil}

Pensar a infodemia como um problema de Saúde Pública significa, também, atentar-se para os fatores de riscos decorrentes da divulgação de pesquisas sem resultados definitivos e conclusivos, assim como não confundir fato científico com hipóteses científicas baseadas em estudos que estão em andamento, como é o caso da garantia de segurança da saúde pública quanto ao uso de medicamentos. A exemplo disso, antes do dia 27 de março de 2020, quando a Agência Nacional de Vigilância Sanitária (Anvisa) autorizou o uso da cloroquina e da hidroxicloroquina a nível de teste para o tratamento da Covid19, vários boatos surgiram nas mídias sociais - alguns deles reforçados pelo presidente da república brasileira, Jair Bolsonaro que esse medicamento seria eficaz no tratamento contra a Covid-19.

Grande parte dos boatos circularam a partir de uma escassa fundamentação ou comprovação científica de estudos randomizados acerca da eficácia da cloroquina, bem como da segurança de uso do medicamento. O próprio Ministério da Saúde, na pessoa do então ministro Luiz Henrique Mandetta, afirmou em boa parte de suas coletivas à imprensa que não concordava com o uso indiscriminado do medicamento (Brasil, 2020). Isto, devido a duas razões: 1) por não haver evidências que a cloroquina, de fato, atuava positivamente no tratamento da Covid-19; 2) o medicamento poderia causar efeitos colaterais e piorar o quadro clínico das pessoas infectadas pela Covid-19.

Ainda que a cloroquina possa vir a ser atestada como eficaz e segura no tratamento da Covid-19, o fato é que a veiculação da informação de que ela é efetiva para o tratamento da doença levou a uma busca desordenada pelo medicamento, baixando os estoques em algumas farmácias do país, prejudicando pessoas que fazem uso dessa medicação para outras causas, conforme noticiado em jornais de grande circulação, a exemplo da Folha de São Paulo (Brasil, 2020).

Artigo de Almeida Filho (2020) sobre o uso da cloroquina sugere que a produção e veiculação de notícias falsas encontram na ansiedade e no medo da população, o terreno fértil para se propagarem. Isso decorre da tentativa de se sustentar em qualquer mínima esperança que lhes pareça razoável e, se agrava ainda mais, porque "a produção de notícias falsas [...] é uma ação desonesta e criminosa. Infelizmente, essas fraudes continuarão circulando [...] num país em que o próprio presidente é um agente infeccioso de desinformação e desmobilização" (Almeida Filho, 2020).

Neste caso, a desinformação como retrato da infodemia colocou em risco a Saúde Pública à medida que as pessoas passaram a querer ou fazer uso da cloroquina sem orientação médica, sem comprovação de estudos randomizados acerca da sua eficácia contra a Covid-19 e, sobretudo, colocou em risco as vidas das pessoas que são, de fato, dependentes do medicamento para os quais o uso é insubstituível e sua ausência pode levar à morte. "Por essa razão, especificamente no caso da divulgação de pesquisas, é preciso tomar cuidado para não difundir resultados preliminares ou hipóteses como dados inconclusivos [...]" (Pierro, 2020). 


\subsection{Caso do álcool no Irã}

A falta de cuidado e devido tratamento com informações produzidas e propagadas são um dos fatores que podem expor as vidas das pessoas a riscos. Recentemente, o Portal de Notícias Uol publicou que 27 pessoas morreram no Irã após ingerirem álcool adulterado, pois tiveram acesso à informação que esta substância curava a Covid-19 (Brasil, 2020). Esse caso é um alerta que serve de exemplo para o dano causado pela propagação de uma fake news, que provocou a morte de 27 pessoas devido ao processo de intoxicação que sofreram depois de ingerirem o álcool.

Em contraste com a informação falsa propagada, de acordo com os estudos desenvolvidos por Sabino et al. (2009, p. 187), "o consumo de álcool inibe tanto de forma direta como indireta o sistema imune", além disso a ingestão exagerada ou descuidada de álcool pode deixar as pessoas mais vulneráveis a infecções, principalmente do sistema respiratório e propensas a problemas cardíacos (Lima, et al., 2013; Almeida, Fook, \& Mariz, 2016).

Nesse caso, considerando que o sistema respiratório é fortemente atingido pela Covid-19 que cursa com tosse seca, febre, cansaço e dor na garganta são os principais sinais da doença, o consumo abusivo - proveniente ou não do falso boato de cura da Covid-19 por meio da ingestão de álcool - deprime o sistema imunológico possibilitando que o corpo se torne mais exposto a ser acometido por infecções que podem agravar a infecção pela Covid-19, além de outras complicações provenientes de substâncias tóxicas presentes.

Tanto o caso da cloroquina quanto da ingestão de álcool serve de alertas que informações médicas e farmacológicas pouco fundamentadas do ponto de vista científico ou o uso inadequado de substâncias sem a devida orientação de profissionais da saúde podem produzir danos ao organismo. No caso do Brasil, onde $70 \%$ da população é dependente exclusivamente do Sistema Único de Saúde (Sus) e que o perfil da maior parte dos seus usuários diretos ainda é formada por pessoas com baixa escolaridade, baixo acesso à informação e à renda, a ocorrência de efeitos colaterais relacionados a medicamentos ou substâncias pouco efetivos para determinadas doenças poderiam contribuir para sobrecarregar o sistema de saúde que já apresenta dificuldades organizacionais e estruturais devido o seu subfinanciamento crônico (Ribeiro, et al., 2006; Santos, 2018).

\subsection{Caso das máscaras cirúrgicas importadas da China}

Na mesma linha de difusão de informações falsas relacionadas à Covid-19 com implicações no campo da saúde pública e social, o Portal de Notícias G1 verificou a veiculação nas redes sociais de mensagens que máscaras importadas da China estariam contaminadas com a Covid-19 e sendo distribuídas para as populações (Brasil, 2020). As mensagens orientavam que as pessoas deveriam evitar o uso das máscaras e, caso utilizassem, deveriam lavá-las com água sanitária.

Diante dessa mensagem alarmista, tanto o Ministério da Saúde da China quanto o Ministério da Saúde do Brasil, bem como a Organização Mundial da Saúde afirmaram que se tratava de uma fake news, visto que - além dos insumos passarem por todo rigor de fabricação que garanta a segurança e saúde dos usuários - infectologistas e especialistas explicam que, ainda que o Brasil recebesse máscaras que foram utilizadas por pessoas infectadas pela Covid-19, não haveria o menor risco de contaminação, uma vez que o tempo de deslocamento em viagem desses insumos seria superior, em tese, ao tempo que o vírus sobrevive fora do corpo. Assim, considerando esses dois aspectos (rigor na fabricação e tempo - em tese - de sobrevivência do vírus), especialistas afirmaram que não havia problema algum em comprar insumos da China.

No tocante à propagação de notícias falsas ou pouco fundamentadas, o Ministério da Saúde afirmou, ainda, que as mensagens veiculadas através de áudios e textos são mais um dos casos de fake news relacionados à pandemia da Covid-19, haja vista que não existem evidências que os insumos encaminhados pela China para o Brasil estivessem contaminados pela Covid-19 ou que apresentem quaisquer riscos à saúde da população. Ao mesmo tempo, a OMS reiterou na ocasião que não há razões para duvidar da garantia de segurança à saúde pública por parte dos produtos provenientes da China. 
Esse caso, por sua vez, assume uma proporção com implicações para a saúde à medida que a propagação dessa informação contribui para que uma parcela da população reduza o uso das máscaras ou deixe de utilizá-las, tendo em vista que a maior parte dos insumos utilizados pelas populações é oriunda da China, por ser este o país com maior potencial de produção. Além disso, as mensagens falsas colaboram para que as pessoas descredibilizem as orientações dos órgãos de saúde e desconfiem da efetiva responsabilidade do Ministério da Saúde e OMS, por exemplo, com a saúde pública e o rigor do trabalho desenvolvido pela vigilância sanitária (Cavalcante, et al., 2021; Rodrigues, et al., 2021).

\subsection{Implicações sociais, econômicas e políticas}

No campo social, é inegável que as mensagens falsas relacionadas à importação de máscaras da China influenciam para o acirramento de atitudes e posicionamentos preconceituosos, xenofóbicos e eugênicos, tendo em vista a sobrecarga de comentários e posturas que expressam a visão das pessoas sobre os chineses como impuros, maus e que, portanto, o mundo precisa passar por uma limpeza para se livrar deles. Boaventura de Sousa Santos (2020), em sua obra "A Cruel Pedagogia do Virus", chama a atenção que

o modo como foi inicialmente construída a narrativa da pandemia nos media ocidentais tornou evidente a vontade de demonizar a China. As más condições higiênicas nos mercados chineses e os estranhos hábitos alimentares dos chineses (primitivismo insinuado) estariam na origem do mal (Santos, 2020, p. 08).

Para o autor, de acordo com a OMS, ainda que não se tenham evidências acerca do local de origem da Covid-19, em muitos discursos oficiais mundiais, como dos Estados Unidos, é "comum" utilizarem as expressões "coronavírus chinês" e "vírus estrangeiro". Obviamente que nas entrelinhas dessas expressões há questões de natureza política, social e econômica, uma vez que é sabido que a China se constitui uma das maiores potências mundiais econômicas no ramo da produção de tecnologia. Assim, por trás das fake news que circulam relacionadas à China, estaria a intenção de "[...] neutralizar a liderança da China em quatro áreas: o fabrico de telemóveis, as telecomunicações de quinta geração (a inteligência artificial), os automóveis eléctricos e as energias renováveis" (Santos, 2020, p. 08).

Atrelado às questões de ordem econômica e política, as notícias falsas divulgadas sobre a China revelam, ainda, a construção e fortalecimento da retórica eugenista à medida que - utilizando-se do discurso da falta de higiene e "impureza" dos chineses - contribui-se para a promoção da ideia de superioridade de uma população sobre a outra e para o enfraquecimento da globalização, sob a justificativa que um grupo social é superior a outro; fator que colabora para a intensificação dos binarismos sociais que dividem os povos entre quem sabe e quem não sabe, quem pode e quem não pode, privilegiados e desfavorecidos, puros e impuros, tal como Hitler acreditava e pregava acerca da necessidade de uma higienização racial que garantisse o predomínio ariano puro e extinguisse negros, deficientes mentais, homossexuais, ciganos e judeus, cujo pensamento levou milhões de pessoas à morte em campos de concentração durante o nazismo na Segunda Guerra Mundial.

De origem milenar e grega, o termo eugenia significa "bem nascido"; constituído como um processo de segregação humana construído social e historicamente e que, ao longo dos anos e em algumas culturas, foi legitimando a ideia da segregação hierárquica como natural e válida (Teixeira \& Silva, 2017). Na atualidade, comportamentos eugenistas podem ser estimulados pela propagação de informações falsas à medida que contenham julgamento moral que reforça ideias semelhantes e naturaliza a desigualdade e o racismo, em detrimento da valorização da diversidade e da vida.

Se desde as sociedades consideradas primitivas a lógica de segregação hierárquica já existia, a propagação de notícias e informações falsas também não é um fenômeno específico e peculiar dos meios de comunicação do tempo presente. A diferença da época atual para as anteriores está na velocidade com que as informações são produzidas, acessadas e difundidas, especialmente com a criação das redes sociais e mídias digitais (D’ancona, 2018; Zarocostas, 2020). 
Além disso, tem-se o fato que - diante do grande número de fake news produzidas diariamente nas mais diversas áreas do conhecimento - as pessoas têm se tornado indiferentes às meias-verdades, quase-mentiras e falácias (D'ancona, 2018) e, por vezes, as informações falsas que deveriam ser encaradas como exceção assumem o lugar de verdades e geram desestabilização nos variados setores e instâncias sociais, a exemplo da Saúde Pública.

A esse respeito, ao referir-se às malícias que sustentam a propagação de fake news, em especial nas mídias sociais Almeida Filho (2020) afirma que:

Em tempos de pandemia, tão perigosas quanto as fake news são as meias-verdades, as quase-mentiras e as falácias. Igualmente virulentas podem ser as verdades, quando manipuladas em jogos maliciosos de linguagem e lógica. Mentiras se desmascaram em mais ou menos tempo, mal-entendidos e meias-verdades eventualmente se esclarecem, falácias podem ser desconstruídas (com maior ou menor esforço). Mas é muito difícil combater a desonestidade retórica embutida em argumentos que contêm verdades, porque o sujeito que as enuncia e propaga tem má-intenção, e por isso se esquiva do debate e reage de modo socialmente irresponsável (Almeida Filho, 2020).

O autor reforça a evidência das implicações negativas advindas da propagação de notícias e informações falsas para a Saúde Pública, principalmente num período de pandemia coronaviral. Por estar envolta por intencionalidades de cunho ideológico, econômico, político, social e cultural, elas trazem uma série de "armadilhas" e dispositivos que objetivam deturpar a verdade e fortalecer a poluição cibernética (Rais, 2018), ocasionando em riscos e prejuízos para o cotidiano das pessoas.

Por isso, as fake news não devem ser vistas como um modismo da atualidade, como se nada representassem ou não estivessem cerceadas do sentido de verdade. Seus produtores e disseminadores são seres reais e as fake news não são neutras ou imparciais; e, como produtora de comportamentos, subjetividades e discursos, a disseminação de informações falsas e infundadas está a serviço de determinados perfis de sujeitos, grupos sociais e organizações que funcionam como uma grande indústria de produção em massa e em série da cultura da desinformação.

Quanto a este aspecto, é importante considerar que o rompimento com o caráter nocivo das fake news requer uma mudança de postura das populações ao produzir e disseminar informações. É necessário que a indiferença passe a dar lugar à busca pela qualidade da fonte produtora das informações, ainda que se saiba que dentro do contexto de algumas realidades, como aquele em que se insere a sociedade brasileira, nem sempre a filtragem da informação é uma escolha do receptor, processo que está relacionado, também, a questões estruturais de acesso a educação e informação que possibilite questionar a veracidade dos conteúdos recebidos.

Em outras palavras, no contexto em que é possível fazer esse julgamento, significa dizer que:

O acesso a informações selecionadas e de boa qualidade demanda, portanto, uma postura ativa do receptor para buscálas nas fontes mais confiáveis, refletir e analisar criticamente todo o conteúdo que lhe é apresentado como novo. Entretanto, tal procedimento demanda ao interessado um custo significativo, que pode ser desdobrado nas seguintes espécies: (a) custo do acesso à informação; (b) custo do tempo para que a informação seja apreendida e assimilada; e (c) custo cognitivo para compreender em profundidade o significado da informação (Cruvinel, 2018, p. 208).

Tomando como base Cruvinel (2018), referindo-se aos pilares "acesso, tempo e cognição", é possível afirmar que, no campo das Ciências Sociais em Saúde, a falta de tratamento à informação pode ser um fator que colabora para a propagação de notícias e informações falsas sobre a Covid-19 e, consequentemente, provoca e fortalece a descrença nas orientações das representações oficiais de saúde, que podem implicar em outras dimensões da vida. 


\section{Considerações Finais}

A produção e propagação de notícias falsas, denominadas fake news, têm sido alvo dos atuais debates nas diversas instâncias e áreas do conhecimento. Este fenômeno se constitui na mais nova expressão dos paradigmas pós-modernos, pois quando disseminadas rapidamente através de mídias sociais, as fake news exercem poder nas relações econômicas, políticas, sociais e culturais. Não se pode perder de vista que tal produção e propagação estão sustentadas por intencionalidades e ideologias que buscam, sobretudo, manipular os comportamentos e pensamentos das pessoas e alimentar interesses específicos.

No campo da Saúde Pública, as informações falsas produzidas no bojo da pandemia de Covid-19 geram implicações negativas que podem comprometer em alto nível a saúde das populações, as relações humanas e a efetividade do trabalho realizado pelas representações oficiais de saúde, sobretudo para aqueles que estão situados nas camadas mais baixas da sociedade e que, portanto, apresentam maior grau de vulnerabilidade.

À medida que a propagação de informações falsas se utiliza de mecanismos que atingem, direta ou indiretamente, os anseios e a esperança das pessoas em busca de uma cura ou proteção contra a Covid-19, a verdade acaba sendo relativizada e as informações falsas assumem lugar de prestígio e relevância porque, por vezes, têm "cara" de verdade, expressões linguísticas que denotam verdade, são ditas por representantes políticos em tom de verdade e, por isso, alcançam as subjetividades das pessoas e agem sobre seus comportamentos, posturas e posicionamentos diante da vida (Ribeiro, et al., 2006).

Em detrimento dos fatos, a Saúde Pública tem testemunhado nos últimos meses, devido à pandemia da Covid-19, o aumento da produção e propagação em massa de informações falsas, que vão desde informações que orientam a adesão a determinados tratamentos como caminho propício à cura, passando pelas falácias sobre atitudes delituosas de países que fornecem insumos até à indicação de medicamentos e substâncias sem nenhuma comprovação científica para os casos da Covid-19.

Em vista disso, é perceptível a maximização da responsabilidade, compromisso e exercício da função social de instituições e universidades no combate às fake news no campo da Saúde Pública, que têm utilizado de plataformas digitais para informar às populações sobre a Covid-19, bem como acerca dos sistemas saúde e, ao mesmo tempo, barrar o crescimento da cultura da desinformação.

As ações de instituições de saúde, segmentos organizados da sociedade e universidades colocam em evidência que, paralelamente, à luta para combater a Covid-19, há também esforços para o enfrentamento à infodemia que, quando não contribui para o clima de pânico, medo e apreensão nas populações, é igualmente nociva pelos conteúdos que carrega e propaga. O caráter danoso que tem, portanto, se torna maior ainda para as pessoas com baixas oportunidades de acesso à diversidade de fontes de informação, de modo que possam compará-las, questioná-las e contrastá-las; ficando assim - por vezes - vulneráveis a fontes não fidedignas e confiáveis, que acabam assumindo o sentido de verdade.

Desse modo, a melhor maneira de evitar os riscos para a saúde decorrentes da propagação de notícias e informações falsas é sempre desconfiar de informações, notícias e discursos que não são fundamentados em evidências ou que não tenham comprovação. Por isso, é fundamental salientar a necessidade de maiores reflexões e estudos no tocante aos pilares "acesso, tempo e cognição" pertinentes ao tratamento dado às informações, às fontes de informação, para quem e sob quais objetivos são produzidas essas informações, bem como quais efeitos as fake news podem causar à saúde pública a curto, médio e longo prazos.

\section{Agradecimentos}

Este trabalho recebeu apoio Conselho Nacional de Desenvolvimento Científico e Tecnológico - CNPq, números de concessão 431990 / 2018-2 e 313423 / 2019-9 e da Fundação de Amparo à Pesquisa do Estado da Bahia - Fapesb, número 


\section{BOL0882/2019.}

\section{Referências}

Almeida Filho, N. (2020). A cloroquina e a epidemiologia clínica. https://www.abrasco.org.br/site/outras-noticias/opiniao/a-cloroquina-e-a-epidemiologiaclinica/46828/

Almeida Filho, N. (2020) Fake News, quase mentiras, meias verdades, falácias e malícias. https://www.abrasco.org.br/site/noticias/opiniao/fake-news-quasementiras-meias-verdades-falacias-e-malicias-artigo-de-naomar-de-almeida-filho/46556

Almeida, T. S. O., Fook, S. M. L., \& Mariz, S. R. (2016). Associação entre etilismo e subsequente Hipertensão Arterial Sistêmica: uma revisão sistemática. Rev Saúde e Ciência. 5(1):76-90. Recuperado em 29 abr. 2020, de http://www.ufcg.edu.br/revistasaudeeciencia/index.php/RSC-UFCG/article/view/328/229

Brasil. Fiocruz. (2020). Pesquisa revela dados sobre 'fake news' relacionadas à Covid-19. https://portal.fiocruz.br/noticia/pesquisa-revela-dados-sobre-fakenews-relacionadas-covid-19

Brasil. Folha de São Paulo. (2020). Pacientes que usam hidroxicloroquina já não acham o remédio em farmácias. https://www1.folha.uol.com.br/equilibrioesaude/2020/03/pacientes-que-usam-hidroxicloroquina-ja-nao-acham-o-remedio-em-farmacias.shtml

Brasil. Ministério da saúde. (2020). Cloroquina poderá ser usada em casos graves do coronavinus. https://www.saude.gov.br/noticias/agencia-saude/46601-cloroquinapodera-ser-usada-em-casos-graves-do-coronavirus

Brasil. Portal de Notícias G1. (2020). É \#FAKE que máscaras importadas da China são distribuídas contaminadas com o novo coronavírus. https://g1.globo.com/fato-ou-fake/coronavirus/noticia/2020/04/20/e-fake-que-mascaras-importadas-da-china-sao-distribuidas-contaminadas-com-o-novocoronavirus.ghtml

Brasil. Portal de Notícias Uol. (2020). Após fake news sobre cura de covid-19, 27 morrem no Irã por ingestão de álcool adulterado. https://noticias.uol.com.br/saude/ultimas-noticias/afp/2020/03/09/vinte-e-sete-pessoas-morrem-no-ira-depois-de-beber-alcool-adulterado-para-curar-covid19.htm

Brocke, J. V., Simons, A., Niehaves, B., Niehaves, B., Reimer, K., Plattfaut, R., \& Cleven, A. (2009). Reconstructing the giant: On the importance of rigour in documenting the literature search process. Proceedings of the European Conference on Information Systems (ECIS), 8-9 June, Verona, Italy.

Cavalcante, W. S., Almeida, A. G. C. dos S., Lima, A. A., Nunes, I. C. M., Nagliate, P., \& Sarmento, P. de A. Recomendações quanto ao uso de máscaras/ respiradores de proteção por profissionais de saúde em risco de exposição ao sars-cov-2: scoping review. Research, Society and Development, 10(1), e16710111628, http://dx.doi.org/10.33448/rsd-v10i1.11628

Chan, A. K. M., Nickson, C. P., Rudolph, J. W., Lee, A., \& Joynt, G. M. (2020). Social media for rapid knowledge dissemination: early experience from the COVID-19 pandemic. Anaesthesia,1-4.

Cruvinel, D. M. (2018). Fake news e o custo da informação. In: Rais D. Fake news: a conexão entre a desinformação e o direito. São Paulo: Thomson Reuters Brasil, 205-220.

D'ancona, M. (2018). Pós-verdade: a nova guerra contra os fatos em tempos de fake news. Faro Editorial.

Gallotti, R., Valle, F., Castaldo, N., Sacco, P., \& Domenico, M. de. (2020). Assessing the risks of "infodemics" in response to COVID-19 epidemics, 1-29. http://arxiv.org/abs/2004.03997

Hua, J., \& Shaw, R. (2020). Corona virus (Covid-19) "infodemic” and emerging issues through a data lens: The case of china. Int J Environ Res Public Health, 17(7).

Kitchenham, B. A., \& Charters, S. (2007). Guidelines for performing systematic literature reviews in software engineering, Technical Report EBSE-2007-01, School of Computer Science and Mathematics, Keele Universit.

Langbecker, A., Castellanos, M. E. P., \& Catalan-Matamoros, D. (2019). O que os valores-notícia podem nos dizer sobre o Sistema Único de Saúde? Explorando aportes teórico-conceituais da noticiabilidade. Interface - Comun Saúde, Educ. http://www.scielo.br/scielo.php?script=sci_arttext\&pid=S1414$32832019000100225 \&$ tlng $=\mathrm{pt}$

Lima, M. C. P., Kerr-Côrrea, F., Rehm, J., Lima, M. C. P., Kerr-Côrrea, F., \& Rehm, J. (2013). Consumo de álcool e risco para doença coronariana na região metropolitana de São Paulo: uma análise do Projeto GENACIS. Rev Bras Epidemiol. 16(1):49-57. http://www.scielo.br/scielo.php?script=sci_arttext\&pid=S1415-790X2013000100049\&lng=pt\&tlng=pt

Mesquita, C. T., Oliveira, A., Seixas, F. L., Paes, A., \& Swift, J. (2020). Infodemia. Fake News and Medicine: Science and The Quest for Truth, 0-2.

Minayo, M. C. (2013). Ciência, técnica e arte: o desafio da Pesquisa Social. Minayo M. C. Pesquisa social: teoria, método e criatividade. Petrópolis: Vozes, 9 29.

Minayo, M. C. S. (2010). O desafio do conhecimento: pesquisa qualitativa em saúde. (13a ed.) Hucitec.

Pennycook, G., \& Rand, D. G. (2019). Fighting misinformation on social media using crowdsourced judgments of news source quality. Proc Natl Acad Sci. 116(7):2521-6. https://www.pnas.org/content/116/7/2521

Pereira, A. S., Shitsuka, D. M., Parreira, F. J., \& Shitsuka, R. (2018). Metodologia da pesquisa científica. UFSM, NTE.

Pierro, B. de. (2020). Epidemia de fake news. https://revistapesquisa.fapesp.br/2020/04/07/epidemia-de-fake-news/ 
Research, Society and Development, v. 10, n. 2, e59810212998, 2021

(CC BY 4.0) | ISSN 2525-3409 | DOI: http://dx.doi.org/10.33448/rsd-v10i2.12998

Rais, D. (2018). Fake news e eleições. RAIS D. Fake news: a conexão entre a desinformação e o direito. Thomson Reuters Brasil, 105-129.

Ribeiro, M. C. S., Barata, R. B., Almeida, M. F., \& Silva, Z. P. (2006). Perfil sociodemográfico e padrão de utilização de serviços de saúde para usuários e não-usuários do SUS PNAD 2003. Ciênc. Saúde Coletiva, 11:1011-22.

Rodrigues, N. P. A., Silva, D. R. da, Garcia Júnior, É. A., Silva Júnior, E. F. da S., Gomes, R. da S., Fernandes, K. F. D., \& Oliveira, K. Á. R. de. (2021). Divulgação de informações sobre higiene e mudança de hábitos durante a pandemia da Covid-19. Research, Society and Development, 10(1), e30910111739, (CC BY 4.0) http://dx.doi.org/10.33448/rsd-v10i1.11739

Sabino, K. R., Machado, A. N., Petroianu, A., Alberti, L. R., Jorge, C., \& Simal, R. (2009). Influência do alcoolismo agudo na função fagocitária do sistema mononuclear fagocitário em modelo experimental phagocyte system in an experimental model, 7:187-9.

Sacramento, I., \& Paiva, R. (2020). Fake News, WhatsApp e a vacinação contra febre amarela no Brasil. Matrizes 14(1), 79-106. http://www.revistas.usp.br/matrizes/article/view/160081.

Santos, B. S. (2020). A cruel pedagogia do vírus. Edições Almedina.

Santos, N. R. dos. (2018). SUS 30 anos: o início, a caminhada e o rumo. Ciência \& Saúde Coletiva, v. 23, n. 6, 1729-1736. Recuperado em 18 jul. 2020 , de $<$ https://doi.org/10.1590/1413-81232018236.06092018>. https://doi.org/10.1590/1413-81232018236.06092018.

Sousa, A. A. de S., Pinho, D. N. C. de, Silva, D. H. C. dos S., Silva, M. C. F. da, Ferreira, D. V. G., Soares, F. da C., Coelho, A. A. S., Braga, F. C. de S., Bezerra, A. M. A., Lima, S. B. de A., Silva, L. de O. R. da, \& Silva Júnior, A. F. da. (2021). Análise dos casos de COVID-19 e de dados sociodemográficos nas mesorregiões do estado do Pará. Research, Society and Development, 10(2), e3210212086, http://dx.doi.org/10.33448/rsd-v10i2.12086

Teixeira, I. M., \& Silva, E. P. (2017). História da eugenia e ensino de genética. História da Ciência e Ensino, construindo interfaces, 2178-2911, 15:63.

Vosoughi, S., Roy, D., \& Aral, S. (2018). News On-line. Science (80- ), 1151(March): 1146-51.

Who. (2020). Situation Report 13. Recuperado em 27 abr. 2020, de https://www.who.int/ docs/default-source/coronaviruse/situation-reports/ 20200202-sitrep13-ncov-v3.pdf?sfvrsn=195f4010_6.

Zarocostas, J. (2020). How to fight an infodemic. Lancet (London, England), 395(10225):676. http://dx.doi.org/10.1016/S0140-6736(20)30461-X 